\title{
Clinical effectiveness of telmisartan alone or in combination therapy for controlling blood pressure and vascular risk in the elderly
}

This article was published in the following Dove Press journal:

Clinical Interventions in Aging

2 December 2010

Number of times this article has been viewed

\section{Bodh I Jugdutt}

Division of Cardiology, Department of Medicine, University of Alberta and Hospital, Edmonton, Canada
Correspondence: $\mathrm{BI}$ Jugdutt 2C2 Walter MacKenzie Health Sciences Centre, Division of Cardiology, University of Alberta Hospital, Edmonton, Alberta, T6G 2R7, Canada

Tel +l 7804390745

Fax +I 7804373546

Email bjugdutt@ualberta.ca

\begin{abstract}
Elderly patients (age $\geq 65$ years) with hypertension are at high risk for vascular complications, especially when diabetes is present. Antihypertensive drugs that inhibit the renin-angiotensin system have been shown to be effective for controlling blood pressure in adult and elderly patients. Importantly, renin-angiotensin system inhibitors were shown to have benefits beyond their classic cardioprotective and vasculoprotective effects, including reducing the risk of new-onset diabetes and associated cardiovascular effects. The discovery that the renin-angiotensin system inhibitor and angiotensin II type $1\left(\mathrm{AT}_{1}\right)$ receptor blocker (ARB), telmisartan, can selectively activate the peroxisome proliferator-activated receptor- $\gamma$ (PPAR $\gamma$, an established antidiabetic drug target) provides the unique opportunity to prevent and treat cardiovascular complications in high-risk elderly patients with hypertension and new-onset diabetes. Two large clinical trials, ONTARGET (Ongoing Telmisartan Alone in combination with Ramipril Global Endpoint Trial) and TRANSCEND (Telmisartan Randomized AssessmeNt Study in ACE-I iNtolerant subjects with cardiovascular disease) have assessed the cardioprotective and antidiabetic effects of telmisartan. The collective data suggest that telmisartan is a promising drug for controlling hypertension and reducing vascular risk in high-risk elderly patients with new-onset diabetes.
\end{abstract}

Keywords: elderly, hypertension, telmisartan, angiotensin II type 1 receptor blocker, peroxisome proliferator-activated receptor- $\gamma$, diabetes, vascular risk

\section{Introduction}

The worldwide increase in the elderly population (age $\geq 65$ years) is associated with concurrent increases in prevalence of systemic hypertension and morbidity and mortality from vascular complications of hypertensive disease. ${ }^{1}$ The elderly population with hypertension and new-onset diabetes is at especially high risk for vascular complications. ${ }^{1}$ Antihypertensive drugs that inhibit the renin-angiotensin system have been shown to control blood pressure effectively in adult and elderly patients. ${ }^{2-8}$ Importantly, renin-angiotensin system inhibitors have been shown to have benefits beyond their classic cardioprotective and vasculoprotective effects, including reducing the risk of new-onset diabetes. ${ }^{2,3}$ Evidence from randomized clinical trials suggests that this may be a class effect of the renin-angiotensin system inhibitors. Recently, the ability of the renin-angiotensin system inhibitor and angiotensin II type $1\left(\mathrm{AT}_{1}\right)$ receptor blocker (ARB), telmisartan, to activate the peroxisome proliferator-activated receptor- $\gamma(\operatorname{PPAR} \gamma)$ selectively, an established antidiabetic drug target, provides the unique opportunity to prevent and treat cardiovascular complications in high-risk elderly patients with hypertension and new-onset diabetes. ${ }^{9-13}$ Telmisartan has been shown to have beneficial effects 
on hypertension, as well as lipid and glucose metabolism, ${ }^{9-13}$ without the side effects of fluid retention, weight gain, and heart failure associated with thiazolidinedione ligands of PPAR $\gamma .{ }^{14}$ Combined renin-angiotensin system inhibition and selective PPAR $\gamma$ modulation with telmisartan could therefore provide additional protection in elderly hypertensive patients with new-onset diabetes compared with renin-angiotensin system inhibition alone.

Recently, two large randomized clinical trials, ONTARGET (Ongoing Telmisartan Alone in combination with Ramipril Global Endpoint Trial) ${ }^{15,16}$ and TRANSCEND (Telmisartan Randomized AssessmeNt Study in ACE-I iNtolerant subjects with cardiovascular disease $)^{17,18}$ have assessed the cardioprotective and antidiabetic effects of telmisartan and the angiotensin converting enzyme (ACE) inhibitor ramipril in high-risk, mostly elderly patients. ${ }^{15-18} \mathrm{~A}$ few small studies evaluated the efficacy of telmisartan in elderly patients with primary hypertension alone, ${ }^{19}$ or associated with cerebral infarction, ${ }^{20}$ type 2 diabetes, ${ }^{21}$ and metabolic syndrome. ${ }^{22}$ This article reviews the clinical effectiveness of telmisartan alone or in combination therapy for controlling blood pressure and vascular risk in the elderly.

\section{Who are the elderly people?}

Because aging is a continuous biologic process, there is no biomarker that separates elderly from nonelderly patients. Evidence indicates that aging leads to multiple changes (Tables 1 and 2) that impact cardiovascular physiology and pathophysiology. ${ }^{23}$ The chronologic age of 65 years became the definition of elderly by default. ${ }^{24}$ Data from population studies and randomized clinical trials since the 1950s suggest that this arbitrary cutoff of 65 has clinical relevance. ${ }^{1}$ Thus, the prevalence of hypertension increases progressively with age, but the vascular complications associated with

Table I Biologic changes in cardiovascular aging

- $\downarrow$ Myocyte number, $\uparrow$ myocyte size

- $\downarrow$ Leucocyte telomere length

- Altered neurohumoral pathways

- Altered contractile pathways

- Altered stress response pathways

- Altered responses to injury

- Altered repair responses

- Altered cardiac and arterial responses

- Altered genes

- Altered cellular and mitochondrial function

- Altered immune responses

- Altered metabolism and metabolic reserve

Notes: $\uparrow$, increase; $\downarrow$, decrease.
Table 2 Physiologic changes and pathophysiologic hallmarks of cardiovascular aging

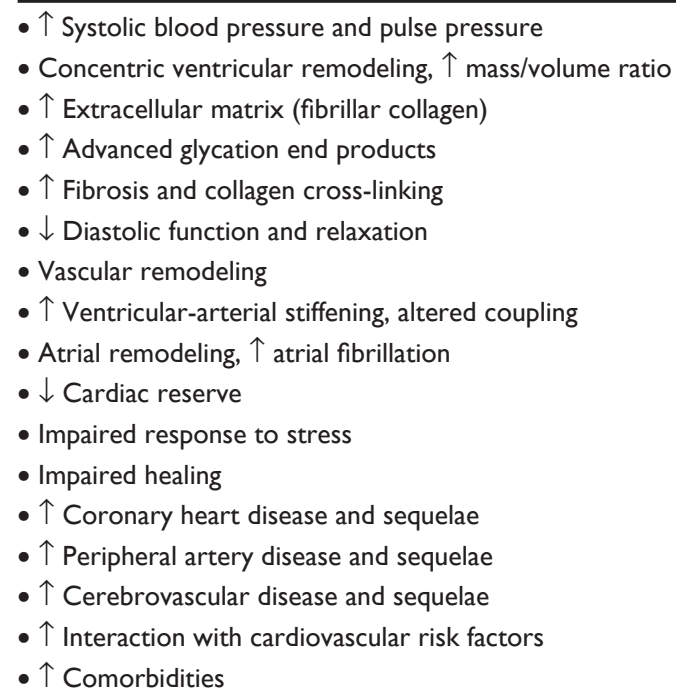

- $\uparrow$ Systolic blood pressure and pulse pressure

- Concentric ventricular remodeling, $\uparrow$ mass/volume ratio

- $\uparrow$ Extracellular matrix (fibrillar collagen)

- $\uparrow$ Advanced glycation end products

- $\uparrow$ Fibrosis and collagen cross-linking

- $\downarrow$ Diastolic function and relaxation

- Vascular remodeling

- $\uparrow$ Ventricular-arterial stiffening, altered coupling

- Atrial remodeling, $\uparrow$ atrial fibrillation

- $\downarrow$ Cardiac reserve

- Impaired response to stress

- Impaired healing

- $\uparrow$ Coronary heart disease and sequelae

- $\uparrow$ Peripheral artery disease and sequelae

- $\uparrow$ Cerebrovascular disease and sequelae

- $\uparrow$ Interaction with cardiovascular risk factors

- $\uparrow$ Comorbidities

Notes: $\uparrow$, increase; $\downarrow$, decrease

hypertension increase sharply after age 65 years, including stroke, myocardial infarction, heart failure, and renal failure. ${ }^{1}$ The same is true for comorbidities such as type 2 diabetes, metabolic syndrome, and obesity, which appear to aggravate the vascular complications. ${ }^{1}$ Importantly, the negative impact of vascular complications increases with aging. ${ }^{1}$ Thus, the risk of dying of myocardial infarction increases progressively across three segments, ie, the younger elderly aged 65-74 years, the older elderly aged $75-84$ years, and the very elderly aged $>85$ years. ${ }^{25}$

\section{The elderly and cardiovascular risk}

Ten points relating to the interaction between aging and cardiovascular risk factors deserve mention. First, evidence indicates that risk factors influence cardiovascular disease progression and aging is an independent predictor of mortality and morbidity. ${ }^{1}$ Second, interactions between risk factors (ie, genetic factors, stress, diet, cigarette smoking, sedentary lifestyle, dyslipidemia, hypertension, obesity, diabetes, and metabolic syndrome) and the cardiovascular system lead to vascular disease (including hypertension) and its complications, including coronary artery disease, myocardial infarction, carotid artery disease, stroke, left ventricular dysfunction, heart failure, peripheral artery disease, and renal failure. ${ }^{1}$ Third, cardiovascular risk factors (including hypertension) contribute to vascular disease progression and end organ pathologies. ${ }^{1}$ Fourth, besides hypertension, comorbidities that are prevalent in the elderly (including coronary artery disease, obesity, and type 2 diabetes) increase risk and accelerate progression toward stroke, myocardial infarction, 
heart failure, renal failure, severe disability, and death. ${ }^{1}$ Fifth, aging increases risk, and cardiovascular disease is more severe and causes more deaths in elderly men and women. Sixth, the Framingham study found six main risk factors for stroke (age, systolic blood pressure, use of antihypertensive therapy, type 2 diabetes, cigarette smoking, and prior cardiovascular disease). ${ }^{26,27}$ Seventh, despite unclear associations between lipids and stroke, ${ }^{27}$ studies with lipid-modifying drugs indicate that dyslipidemia is an important risk factor for stroke. ${ }^{28}$ Eighth, the INTERHEART study, which ranked potentially modifiable risk factors for myocardial infarction in five age groups $(<45,46-55,56-65,66-70,>70$ years $)$, found that nine factors account for most of the risk of myocardial infarction, including abnormal lipids, hypertension, diabetes, and abdominal obesity. ${ }^{29}$ Ninth, patients with evidence of vascular disease such as myocardial infarction, stroke, transient ischemic stroke, and peripheral vascular disease represent a high-risk group for major cardiovascular events and the risk is greater in the elderly. ${ }^{30,31}$ Tenth, the role of hypertension in cardiovascular disease and the ability of antihypertensive drugs to reduce risk are well established. ${ }^{32}$ In older persons with isolated systolic hypertension, a history of diabetes is an important risk factor for lacunar stroke, whereas carotid bruit and age are important risk factors for atherosclerotic and embolic stroke. ${ }^{26}$

\section{Demographics of hypertension in the elderly}

In the US, hypertension defined as blood pressure $\geq 140 / 90 \mathrm{mmHg}$, affects at least 74.5 million of the adult population. ${ }^{1}$ Prevalence increases with age, with half to two-thirds of hypertensives being elderly and $75 \%$ aged $>80$ years. There is a gender difference, with age-adjusted prevalence between 1999 and 2002 being 78\% for elderly women and $64 \%$ for elderly men. The profile of hypertension is altered with aging and there is again a gender difference; systolic blood pressure increases, whereas diastolic blood pressure stays relatively constant between age 50-80 years, with the average diastolic blood pressure higher in men than women. Isolated systolic hypertension without a rise in diastolic blood pressure occurs in $8 \%$ of the population aged 60 years and $>25 \%$ in those aged $>80$ years.

Complications of hypertension increase with age. ${ }^{1}$ The prevalence of silent stroke also increases with aging, being $22 \%$ in those aged $65-69$ years, and $43 \%$ in those aged $\geq 85$ years. Prevalence of myocardial infarction and heart failure is highest in the elderly. ${ }^{1}$ Chronic conditions are also more common in the elderly, most prominent among these being heart disease and diabetes. ${ }^{1}$ Diabetes also increases with aging, with the largest increases projected for the oldest groups. ${ }^{1}$ More than $80 \%$ of all deaths from cardiovascular disease occur in the elderly, with approximately $60 \%$ in those aged $>75$ years. ${ }^{1}$ For 2010 , the estimated total costs (indirect plus direct) in billions are $\$ 76.6$ for hypertensive disease, $\$ 73.7$ for stroke, and $\$ 39.2$ for heart failure, respectively. ${ }^{1}$

\section{Epidemiology of hypertension in the elderly}

The pharmacologic treatment of hypertension has improved since the 1990s. However, hypertension in the elderly does not occur in isolation. Typically, other cardiovascular diseases, comorbidities, and polypharmacy are common, making therapy more challenging. The profile of hypertension, as well as commonly associated cardiovascular diseases, such as coronary heart disease and heart failure, differ from that in nonelderly patients. Systolic hypertension is common and becomes a stronger predictor of cardiovascular events, especially in older women. Heart failure is also more prevalent and heart failure with preserved ejection fraction more common, especially in older women. Coronary artery disease is more common and more likely to involve multiple vessels and the main left artery. Myocardial infarction is more prevalent and is equally distributed in elderly men and women until the age of 80 years, after which it is more frequent in women. The risk of heart failure, severity of hypertension, and hypertension with antecedent myocardial infarction increase with aging. ${ }^{1}$ Myocardial infarction usually results in dilative ventricular remodeling and systolic heart failure, also called heart failure with low ejection fraction. ${ }^{30}$ In contrast, hypertensive disease usually results in concentric remodeling and diastolic heart failure, also called heart failure with preserved ejection fraction. ${ }^{30}$ Nearly $50 \%$ of elderly patients have heart failure with low ejection fraction whereas approximately $50 \%$ of all heart failure patients have heart failure with preserved ejection fraction, and its prevalence is higher in the elderly. ${ }^{30} \mathrm{In}$ a recent study of heart failure with preserved ejection fraction, all patients were very elderly, with a mean age of 87 years. ${ }^{33}$ Whereas pharmacologic therapies for heart failure with low ejection fraction are available, therapies for heart failure with preserved ejection fraction are lacking. ${ }^{30}$ Because elevated blood pressure is the main cause, tight blood pressure control is important for prevention.

Diabetes is not only more prevalent in the elderly, but increases cardiovascular risk, and more so in the presence of hypertension and/or coronary heart disease. ${ }^{1-3}$ Epidemiologic studies showed that the presence of diabetes results 
in increased cardiovascular mortality by nearly three-fold in men and five-fold in women, ${ }^{35}$ increased prevalence of coronary heart disease, ${ }^{36}$ increased risk of cardiovascular disease,${ }^{37}$ and increased risk of renal disease and other macrovascular and microvascular complications. ${ }^{1,38}$

\section{Renin-angiotensin system inhibitors for hypertension \\ and cardiovascular risk in the elderly}

It is well recognized that the renin-angiotensin system plays a central role in regulation of blood pressure, fluid and electrolyte balance, and the pathophysiology of cardiovascular disease (see Figure 1). ${ }^{4-8}$ Angiotensin II, the primary effector peptide of the renin-angiotensin system, not only increases blood pressure but also promotes vascular inflammation, leading to endothelial dysfunction and atherosclerosis, stimulates vascular smooth muscle hypertrophy, and vascular remodeling, and stimulates myocardial fibrosis and hypertrophy, leading to cardiac remodeling. ${ }^{4-8}$ It also increases aldosterone, which stimulates fibrosis and cardiovascular remodeling (see Figure 1). Most of the effects of angiotensin II are mediated via $\mathrm{AT}_{1}$ receptors, providing a rationale for $\mathrm{ACE}$ inhibition and $\mathrm{AT}_{1}$ receptor blockade (see Figure 1). Importantly, aging is associated with increased angiotensin II and other renin-angiotensin system components which, in turn, may contribute to increased cardiovascular remodeling and cardiovascular risk in the elderly. ${ }^{23}$

\section{ACE inhibitors for cardiovascular risk}

Cumulative evidence suggests that renin-angiotensin system activation plays a critical role in increasing cardiovascular events, and renin-angiotensin system inhibition with ACE

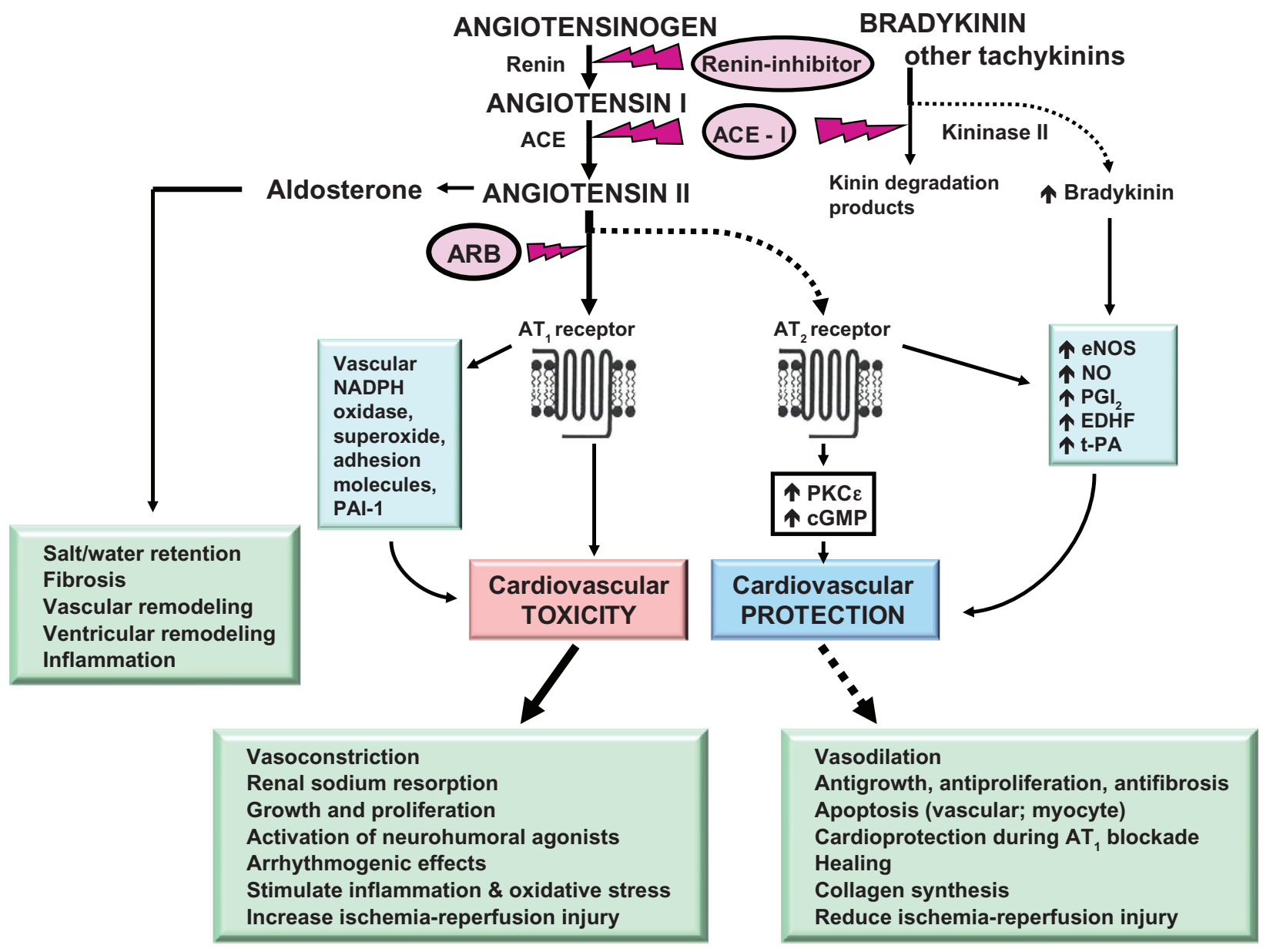

Figure I Pathways of cardiovascular protection induced by ACE inhibition and ARBs.

Abbreviations: cGMP, cyclic guanosine $3^{\prime} 5^{\prime}$ monophosphate; EDHF, endothelin-derived hyperpolarizing factor; eNOS, endothelial nitric oxide synthase; NO, nitric oxide; PAI-I, plasminogen activator inhibitor-I; $\mathrm{PGI}_{2}$, prostacyclin; PKC $\varepsilon$, protein kinase $\mathrm{C} \varepsilon$; t-PA, tissue plasminogen activator; ACE, angiotensin-converting enzyme; $\mathrm{AT}$, angiotensin II type I; ARB, angiotensin II type I (AT, ) receptor blocker; NADPH, nicotinamide adenine dinucleotide phosphate oxidase. Copyright $@$ 2006 . Adapted with permission from Dove Medical Press. Jugdutt BI. Valsartan in the treatment of heart attack survivors. Vasc Health Risk Manag. 2006;2(2):125-38. ${ }^{49}$ 
inhibitors reduces cardiovascular risk. ${ }^{39}$ ACE inhibitors effectively control blood pressure in patients with hypertension, and have additional beneficial effects on cardiovascular risk factors, including coronary heart disease, stroke, myocardial infarction, heart failure, diabetes, and chronic kidney disease. Randomized clinical trials have established that ACE inhibitors reduce rates of death, myocardial infarction, and stroke in patients with heart failure, ${ }^{40}$ left ventricular dysfunction, ${ }^{41}$ vascular disease, ${ }^{42-44}$ and highrisk diabetes. ${ }^{3}$

Four trials specifically addressed whether ACE inhibitors reduce cardiovascular events in low- to high-risk patients. First, the HOPE (Heart Outcomes Prevention Evaluation) study ${ }^{2}$ showed improvement in prognosis using the ACE inhibitor, ramipril, with a decreased rate of death, myocardial infarction, and stroke in a broad range of high-risk patients (including diabetes) for cardiovascular events and without low ejection fraction or heart failure. HOPE decreased new-onset diabetes and complications of diabetes. Second, EUROPA (European trial On reduction of cardiac events with Perindopril in stable coronary Artery disease), ${ }^{42}$ which included patients with coronary artery disease at lower risk than in HOPE and without left ventricular dysfunction, showed improvement in the composite endpoint of cardiovascular mortality, myocardial infarction, and resuscitation. Third, QUIET (QUinapril Ischemic Event Trial), ${ }^{43}$ which included low-risk patients, found no significant benefit. Fourth, the PEACE (Prevention of Events with Angiotensin-Converting Enzyme inhibition) trial, ${ }^{44}$ which included low-risk patients and used the ACE inhibitor, trandolapril, found no significant benefit. However, the dose of the ACE inhibitors in QUIET and PEACE may have been suboptimal. Moreover, a metaanalysis of these trials, with pooled data for 31,600 patients, showed that ACE inhibitors are effective in preventing cardiovascular events, with a $26 \%$ reduction in the risk of heart failure or stroke, and a $13 \%-18 \%$ reduction in total and cardiovascular mortality and myocardial infarction compared with placebo. ${ }^{45}$

Several studies suggested that ACE inhibitors not only reduce stroke by controlling blood pressure but may also prevent renal complications of diabetes. ${ }^{46}$ The HOPE/ TOO (The ongoing Outcomes) study found decreased development of diabetes in the follow-up phase, suggesting an added benefit of long-term ramipril. ${ }^{47}$ In the MICRO (MIcroalbuminuria Cardiovascular and Renal Outcomes) HOPE substudy, ${ }^{3}$ ramipril was beneficial for cardiovascular events and overt nephropathy in patients with diabetes.
In the ADVANCE (Action in Diabetes and Vascular disease: preterAx and diamicroN-MR Controlled Evaluation) trial, the ACE inhibitor, perindopril, together with the diuretic, indapamide, reduced the risks of major vascular events and death in type 2 diabetes. ${ }^{48}$

\section{AT, receptor blockers for cardiovascular risk}

Because ACE inhibitors do not block angiotensin II generated in cardiovascular and other tissues via non-ACE pathways, the ability of ARBs to block angiotensin II at the $\mathrm{AT}_{1}$ receptor selectively, resulting in more complete inhibition, was considered advantageous (see Figure). ${ }^{49}$ Unlike ARBs, ACE inhibitors increase bradykinin by suppressing its degradation, thereby enhancing vasodilation, but also increasing cough and angioneurotic edema that are troublesome in approximately $20 \%$ of patients, especially in women and Asians. ${ }^{2,3,49}$ ARBs may result in unopposed angiotensin II type $2\left(\mathrm{AT}_{2}\right)$ receptor activation and enhance vasodilation via downstream $\mathrm{AT}_{2}$-mediated signaling. ${ }^{49}$ Apart from blocking deleterious effects of angiotensin II and controlling blood pressure, ARBs might have protective effects similar to those of ACE inhibitors. Data from randomized clinical trials showed that ARBs effectively control blood pressure in hypertension and are well tolerated. ${ }^{50}$ However, despite well known arguments for using $\mathrm{ARBs}$, as reviewed previously, ${ }^{49}$ whether ARBs are as effective as ACE inhibitors in reducing events such as stroke and myocardial infarction has been questioned. ${ }^{51}$ Moreover, ARBs can also release kinins and increase bradykinin levels in hypertensive patients, ${ }^{50,52}$ and thereby mediate cardiovascular protection. ${ }^{49}$ Such an ARB-induced increase in bradykinin can augment therapeutic actions, but can also lead to cough and angioedema. ${ }^{50,52}$ In the counterregulatory arm of the renin-angiotensin system, both ACE inhibitors and ARBs can increase angiotensin-(1-7). ${ }^{49}$

A complicating factor with the use of ACE inhibitors in heart failure patients is that angiotensin II levels increase and symptoms worsen. ${ }^{53}$ However, studies in hypertension have shown that ARBs, such as losartan and valsartan, are as effective as ACE inhibitors in lowering blood pressure. ${ }^{54,55}$ In hypertensive patients with ACE inhibitor-induced cough, this complication is less frequent with ARBs. ${ }^{56}$ In patients with heart failure and low ejection fraction, an ARB was shown to reduce the rate of death or hospitalization relative to placebo in those patients who could not tolerate an ACE inhibitor, ${ }^{57}$ or were already receiving one. ${ }^{58,59}$ In the LIFE (Losartan 
Intervention For Endpoint reduction in hypertension) study, compared with beta-blockers, ARBs reduced vascular events in high-risk patients with hypertension and left ventricular hypertrophy. ${ }^{60}$ Taken together, these studies suggest that an $\mathrm{ARB}$ is an effective and well tolerated alternative to an ACE inhibitor for cardiovascular protection.

Because ACE inhibitors preceded ARBs for treating hypertension and heart failure, it has become necessary in clinical trials to demonstrate noninferiority or superiority of an ARB over an ACE inhibitor as comparator. In patients with myocardial infarction, two studies comparing an ARB with an ACE inhibitor produced different results. OPTIMAAL (OPtimal Trial In Myocardial infarction with Angiotensin II Antagonist Losartan) ${ }^{61}$ and VALIANT (VALsartan In Acute Myocardial Infarction Trial) ${ }^{62}$ compared the ARBs, losartan and valsartan, respectively, with the ACE inhibitor, captopril, in patients with signs of heart failure within 10 days of myocardial infarction. In OPTIMAAL, the ARB was not superior and the noninferiority criteria were not met; in fact, there was an increase in cardiovascular mortality after a 2.7-year mean follow-up. ${ }^{61}$ In VALIANT, the ARB was nonsuperior and noninferior for mortality and the composite endpoint of fatal and nonfatal events. The study established that valsartan was as effective as an ACE inhibitor in reducing mortality in high-risk survivors of myocardial infarction. ${ }^{62}$ A meta-analysis of 54,254 patients from 11 trials showed a potential 18\% increase in myocardial infarction with ARBs compared with placebo and a possible increase compared with other active therapy. ${ }^{63}$ In a separate meta-analysis of 55,050 patients from 11 trials that compared ARBs with either placebo or an active comparator, ARBs were found to reduce event rates for stroke, not to reduce event rates for global death, and to increase rates of myocardial infarction by $8 \% .^{51}$ The cloud of doubt cast by these reports has been partly dispelled by studies with the ARB telmisartan. ${ }^{15-18}$

\section{Telmisartan for hypertension and cardiovascular risk}

The $\mathrm{AT}_{1}$ antagonist telmisartan is an orally active, selective, biphenyl, nontetrazole, 6-substituted benzimidazole aminopeptide that has no apparent $\mathrm{AT}_{1}$ agonist activity and does not interact with other receptors involved in cardiovascular regulation. ${ }^{9,64}$ Studies in various experimental models have shown that telmisartan is a more potent antihypertensive agent than losartan, ${ }^{9}$ and reduces glomerulosclerosis and cardiac hypertrophy. ${ }^{9}$ Telmisartan has a long half-life and sustained blood pressure-lowering activity. Studies in patients showed that a telmisartan $80 \mathrm{mg}$ once daily dose was very effective in lowering diastolic blood pressure, ${ }^{65,66}$ with no difference in pharmacokinetics found between healthy elderly and younger subjects. ${ }^{19}$

\section{Potential problems with treatment of hypertension in the elderly}

Treatment of hypertension in elderly patients is more challenging than in the nonelderly because of aging-related biologic (Table 1) and pathophysiologic (Table 2) changes and associated comorbidities and polypharmacy. Common problems are listed in Table 3. Comorbidities, including obesity, metabolic syndrome, and diabetes, not only aggravate the total cardiovascular disease burden but complicate management. Polypharmacy can lead to drug interactions. ${ }^{67,68}$ Typically, elderly patients have multiple drugs prescribed. Patients aged $\geq 65$ years usually use $2-6$ prescription and 1-4 nonprescription drugs on a regular basis. ${ }^{68}$ Addition of other drugs substantially increases the possibility of adverse effects. The potential for an adverse effect of any drug is estimated to increase by $6 \%$ when taken with one drug, by $50 \%$ when taken with five different drugs, and by $100 \%$ when taken with eight or more medications. ${ }^{68}$ Age-related changes in the gastrointestinal tract, body content of fat and water, and liver and renal function, alter drug pharmacokinetics, including absorption, distribution, metabolism, and excretion in the elderly. In addition, elderly patients may have blunted responses to diuretics, ACE inhibitors, beta-blockers, and positive inotropes. They may show heightened sensitivity to renal dysfunction, impairment of sodium and water excretion, postural hypotension, aggravation of hypotension to treatments (ie, ACE inhibitors,

Table 3 Problems with pharmacologic therapy in the elderly

- $\uparrow$ Susceptibility to postural hypotension with treatments

- $\uparrow$ Aggravation of hypotension with treatments

- $\uparrow$ Impaired balance and proprioception with treatments

- $\uparrow$ Susceptibility to sick sinus syndrome and bradyarrhythmias with treatments

- $\uparrow$ Adverse drug reactions and $\downarrow$ compliance

- $\uparrow$ Risk of drug interactions

- Altered pharmacokinetics, impaired metabolism, and clearance of drug treatments

- $\uparrow$ Susceptibility to renal dysfunction with drug treatments

- $\uparrow$ Impaired sodium and water excretion with drug treatments

- Altered response to diuretics, ACE inhibitors, ARBs, beta-blockers, positive inotropes

Notes: $\uparrow$, increase; $\downarrow$, decrease.

Abbreviations: ACE, angiotensin converting enzyme; ARB, angiotensin II type I $\left(A T_{1}\right)$ receptor blocker. 
beta-blockers, ARBs, nitrates, hydralazine, and diuretics) besides cognitive impairment and general frailty. Because of the physiologic changes that occur with aging, several precautionary measures are necessary with the pharmacotherapy of hypertension, myocardial infarction, and heart failure in the elderly. ${ }^{30,67}$ Also because of the age-related changes (Table 3 ) and impact of comorbidities, therapy needs to be individualized.

\section{Telmisartan for hypertension in the elderly}

Given its pharmacodynamic profile, telmisartan appeared well suited for treating hypertension in the elderly, ${ }^{19,69}$ but this needed testing. In a 26-week, multicenter study of 278 elderly patients (aged $\geq 65$ years, mean age 71 years) with primary hypertension, ${ }^{19}$ Karlberg et al used a careful dose titration scheme, starting with $20 \mathrm{mg}$ and escalating to $40 \mathrm{mg}$ and $80 \mathrm{mg}$ of telmisartan based on the blood pressure response, and addition of hydrochlorothiazide if the $80 \mathrm{mg}$ dose was not sufficient. Importantly, the dose of telmisartan was increased from $20 \mathrm{mg}$ to $40-80 \mathrm{mg}$ and enalapril from $5 \mathrm{mg}$ to $10-20 \mathrm{mg}$ at four-week intervals until the trough supine blood pressure was $<90 \mathrm{mmHg}$. Only after 12 weeks, hydrochlorothiazide $12.5-25 \mathrm{mg}$ once daily was added to the treatment regimen of patients who were not controlled on monotherapy. ${ }^{19}$ The study showed that both regimens provided effective lowering of blood pressure over the 24-hour dosing interval based on ambulatory blood pressure monitoring.

Although both regimens were well tolerated, the enalapril regimen was associated with more than double the incidence of treatment-related cough compared with the telmisartan regimen (16\% versus $6.5 \%$, respectively). ${ }^{19}$ The overall findings of that small study suggested that telmisartan is well tolerated and at least as effective as enalapril for treating elderly patients with mild to moderate hypertension. ${ }^{19}$ However, that study did not address cardiovascular risk.

\section{Telmisartan and partial PPAR $\gamma$ agonism}

In addition to renin-angiotensin system inhibition, telmisartan acts as a selective partial agonist of PPAR $\gamma$, an intracellular nuclear hormone receptor that is involved in the regulation of carbohydrate and lipid metabolism. Discovery of this unique property of telmisartan has attracted attention because of its therapeutic potential in elderly patients with obesity, metabolic syndrome, and type 2 diabetes. Several studies have shown that PPAR $\gamma$ plays an important role as a regulator of carbohydrate and lipid metabolism, ${ }^{70,71}$ and ligands for PPAR $\gamma$ improve insulin sensitivity, ${ }^{72}$ reduce triglyceride levels, ${ }^{72}$ decrease risk of atherosclerosis, ${ }^{73}$ reduce vascular and cardiac effects of hypertension, ${ }^{74}$ and promote peripheral vasodilation. ${ }^{75-77}$

Although thiazolidinedione ligands for PPAR $\gamma$ were approved for the treatment of type 2 diabetes, these agents alone do not control blood pressure in hypertension and can provoke weight gain, edema, and heart failure in diabetics. ${ }^{78}$ Despite reported beneficial effects of the thiazolidinediones, ie, pioglitazone and rosiglitazone, in animal models of ischemia-reperfusion injury and postinfarction ventricular remodeling, ${ }^{79-81}$ the finding that rosiglitazone increases mortality post myocardial infarction in rats ${ }^{82}$ led to grave concerns about the use of thiazolidinediones in diabetics. A teleoanalysis of clinical trials showed an increased risk of heart failure with both thiazolidinediones in patients with type 2 diabetes. ${ }^{14}$ More recently, patients treated with rosiglitazone showed an increased risk of myocardial infarction, stroke, heart failure, and death in high-risk elderly diabetics compared with pioglitazone. ${ }^{83}$ These side effects may not be unique to the thiazolidinedione moiety because they can also occur with nonthiazolidinedione ligands. ${ }^{9}$ Thiazolidinedione-induced fluid retention and heart failure appears to be related not to left ventricular dysfunction, ${ }^{9}$ but rather to increased sodium reabsorption mediated by the renal PPAR $\gamma$ pathway in collecting tubules. ${ }^{84}$ Moreover, both thiazolidinediones are under review by the US Food and Drug Administration, and restrictions have been applied with the use of rosiglitazone. The 2010 consensus is that thiazolidinediones should be avoided in older patients with type 2 diabetes and class III/IV heart failure and should not be used for reducing cardiovascular events.

Elegant molecular modeling studies by Benson et $\mathrm{al}^{9}$ established two important points. First, telmisartan is only a partial PPAR $\gamma$ agonist and might influence PPAR $\gamma$ activity by interacting with regions of the ligand-binding domain that are not typically engaged by full PPAR $\gamma$ agonists. Second, other ARBs lack the potential of telmisartan for receptor interaction and have little or no PPAR $\gamma$ activity. Given that renin-angiotensin system blockade with telmisartan can inhibit renal sodium reabsorption and attenuate fluid retention and edema, the potential heart failure complication seen with thiazolidinediones should not be a source of concern with the use of telmisartan in diabetics. ${ }^{9}$

Several other clinical and experimental studies support the beneficial effect of telmisartan via PPAR $\gamma$ activity. First, a small comparative study of telmisartan 40-80 mg and enalapril 10-20 mg in 250 patients with hypertension and early type 2 diabetic nephropathy (age $>40$ years) showed that, over the five-year study period, telmisartan is noninferior 
to enalapril in conferring renoprotection. ${ }^{88}$ Second, another small comparative study of telmisartan $80 \mathrm{mg}$ and losartan $50 \mathrm{mg}$ for three months in 40 patients, mean age 55-56 years, with hypertension and metabolic syndrome, showed that telmisartan provides superior control of blood pressure and displays insulin-sensitizing activity consistent with its partial PPAR $\gamma$ activity. ${ }^{10}$ Third, telmisartan (but not eprosartan) was shown to increase nitric oxide synthesis sufficient to delay aging of human umbilical vein endothelial cells via activation of PPAR $\gamma$ signaling. ${ }^{11}$ Fourth, telmisartan was shown to attenuate fatty acid-induced oxidative stress in mouse pancreatic $\beta$-cells, suggesting that it may preserve insulin secretion capacity in diabetics. ${ }^{12}$ Fifth, a recent small study of 39 patients with essential hypertension (mean age $61 \pm$ 6 years) showed that telmisartan $80 \mathrm{mg}$ daily effectively improved vascular endothelial function and arterial stiffness after eight weeks, consistent with increased PPAR $\gamma$ activity. ${ }^{13}$

The collective evidence suggests that, among the antihypertensive drugs that inhibit the renin-angiotensin system, telmisartan is safe and effective for elderly patients. ${ }^{19}$ Whether its partial PPAR $\gamma$ agonism might be an added advantage for high-risk elderly patients needs further evaluation in larger clinical trials. Pending the results, caution might be prudent.

\section{Do other renin-angiotensin system inhibitors have PPAR $\gamma$ activity?}

Among other ARBs, only irbesartan was found to have significant PPAR $\gamma$ agonist activity, but that was modest compared with telmisartan. ${ }^{9}$ A subsequent prospective observational study in 3259 patients with hypertension and metabolic syndrome or diabetes showed improvement in metabolic parameters with irbesartan $150 \mathrm{mg}$ or $300 \mathrm{mg}$ daily with or without hydrochlorothiazide $12.5 \mathrm{mg}$ daily after six months. ${ }^{85}$ Importantly, these changes were more pronounced in male and obese patients. ${ }^{85}$ However, the mean age of the patients in that study was only $61.5 \pm 10.5$ years. ${ }^{85}$ The renal benefits of ARBs in patients with type 2 diabetes as previously reported with losartan (albeit in patients aged $60 \pm 7$ years), ${ }^{86}$ were most likely due to blockade of the effects of angiotensin II through the $\mathrm{AT}_{1}$ receptor, ${ }^{86}$ and possibly by enhancing effects through the $\mathrm{AT}_{2}$ receptor. ${ }^{87}$ The extensively reported beneficial effects of ACE inhibitors in type 2 diabetes ${ }^{47,48}$ are most likely due to the combined effects of increased bradykinin and decreased angiotensin II via $\mathrm{AT}_{1}$ and $\mathrm{AT}_{2}$ receptors rather than PPAR $\gamma .{ }^{9}$

\section{ONTARGET study}

The ONTARGET investigators compared telmisartan (80 mg daily, $n=8542$ ) with the ACE inhibitor, enalapril $10 \mathrm{mg}$ daily $(\mathrm{n}=8576)$ as the comparator or combined with ramipril as background therapy $(\mathrm{n}=8502)$ in patients with vascular disease or high-risk diabetes over a median of 56 months. ${ }^{15}$ Patients aged $\geq 55$ years were enrolled. Mean ages were $66.4 \pm 7.2,66.4 \pm 7.1$ and $66.5 \pm 7.3$ years, respectively. Mean baseline blood pressures averaged $142 \pm 17 / 82 \pm 10 \mathrm{mmHg}$ in the three groups. Telmisartan was noninferior to or as effective as ramipril for prevention of the composite primary outcome (cardiovascular deaths, myocardial infarction, or heart failure hospitalization) as well as individual components of the outcome. However, blood pressure reduction was greater with telmisartan and combination therapy compared with enalapril monotherapy. Also, compared with enalapril monotherapy, telmisartan monotherapy was associated with less cough ( $1.1 \%$ versus $4.2 \%)$ and angioedema ( $0.1 \%$ versus $0.3 \%)$ and more hypotensive symptoms (2.6\% versus $1.7 \%)$ and similar rates of syncope $(0.2 \%)$. Compared with either monotherapy, combination therapy was associated with more adverse events (hypotensive symptoms, $4.8 \%$ versus $1.7 \%$; syncope, $0.3 \%$ versus $0.2 \%$; renal impairment, $13.5 \%$ versus $10.2 \%$; hyperkalemia [ $>5.5 \mathrm{mmol} / \mathrm{L}]$ : combination therapy [480 patients] versus telmisartan [287 patients] versus ramipril [283 patients], $P<0.001$ ) and without increased benefits.

Five points in ONTARGET deserve emphasis. First, although the population was similar to that in HOPE, ${ }^{2}$ adherence to the ACE inhibitor, ramipril, was higher than in HOPE. ${ }^{15}$ Second, the discontinuation rate was lower and compliance higher with telmisartan than with ramipril. ${ }^{15}$ In previous randomized clinical trials, $20 \%$ of patients were unable to tolerate ACE inhibitors. ${ }^{2,3,45}$ Third, although the population was quite different from that in VALIANT which selected those with left ventricular dysfunction and postinfarction heart failure, VALIANT also showed noninferiority to an ACE inhibitor (ie, captopril). ${ }^{62}$ Fourth, as in VALIANT, ${ }^{62}$ a greater decrease in blood pressure with combination therapy was not associated with greater benefits, likely because of the offsetting effect of increased risk of hypotension, syncope, renal dysfunction, and hyperkalemia. In addition, the potential benefits of dual renin-angiotensin system inhibition may have been blunted by combination with beta-blockers, which were used in approximately 55\% of patients. A similar interaction was noted in VALHeFT (the VALsartan HEart Failure Trial). ${ }^{58}$ Fifth, in contrast with CHARM (Candesartan in Heart Failure - Assessment 
of Mortality and Morbidity), ${ }^{59}$ which enrolled heart failure patients and added the ARB candesartan to an ACE inhibitor in variable doses ( $<50 \%$ on full doses), and VALHeFT, ${ }^{58}$ which enrolled heart failure patients and compared valsartan with a placebo group of which $90 \%$ received background ACE inhibitors in submaximal doses, combination therapy was superior to placebo.

Taken together, the ONTARGET data suggest that there is no added advantage of combination therapy at full doses in older adult and younger elderly patients. Careful titration should be the rule when combining ARBs with ACE inhibitors, both of which are powerful vasodilators, to avoid hypotension, especially in elderly and very old patients. The dose regimen used by Karlberg et al was cautious, wise, and effective. ${ }^{19}$ The harmful paradoxical J-curve or U-curve effect of decreased blood pressure and hypoperfusion with vasodilator therapy was demonstrated for acute myocardial infarction, both in experimental and clinical settings. ${ }^{89-93}$ This is likely true for hypertension, ${ }^{94}$ especially in elderly patients with physiologic increases in cardiac and vascular stiffness (Table 2), although definitive confirmation in appropriate randomized clinical trials of more elderly patient populations is needed. ${ }^{6}$

\section{TRANSCEND study}

By design, TRANSCEND ${ }^{17}$ compared telmisartan $80 \mathrm{mg}$ once daily $(n=2954)$ with placebo $(n=2972)$ in patients intolerant to ACE inhibitors and with cardiovascular disease or diabetes with end-organ damage over a median duration of 56 months. The patients were identified after a three-week run-in period. Mean age was 66.9 years, and baseline blood pressure averaged 141/82 $\mathrm{mmHg}$ for both groups. Their study population included patients selected from ONTARGET because of ACE inhibitor intolerance. Telmisartan was well tolerated, but did not affect the ONTARGET primary outcome (composite of cardiovascular death, myocardial infarction, stroke, or hospitalization for heart failure). However, telmisartan modestly reduced the secondary outcome (composite of cardiovascular death, myocardial infarction, or stroke) compared with placebo (13.0\% versus $14.8 \%$; unadjusted $P=0.048$ and adjusted $P=0.068$ ). Discontinuation was less with telmisartan than placebo $(21.6 \%$ versus $23.8 \%$; $P=0.055)$ and this was mostly for hypotension $(0.098 \%$ versus $0.54 \% ; P=0.049)$; rates of syncope $(1 \%$ versus $0 \%)$, cough $(0.51 \%$ versus $0.61 \%)$, angioedema $(0.07 \%$ versus $0.10 \%)$, and renal dysfunction $(0.81 \%$ versus $0.44 \%)$ were low and not different between the groups. Telmisartan had no effect on rates of hospitalization for heart failure, at least initially in the first six months but showed clear benefit after six months.

Five points in TRANSCEND deserve comment. First, the finding that telmisartan did not reduce the primary composite outcome but reduced the secondary composite outcome that excluded heart failure should be interpreted with caution. The population was especially selected to exclude not only ACEintolerant patients but also patients with heart failure, and few had left ventricular hypertrophy. Selection may have excluded patients at higher risk and those likely to show benefit for heart failure. Hospitalization for heart failure was low for telmisartan and placebo (4.5\% versus $4.3 \%)$, and any heart failure event was also low (6.5\% versus 6.6\%). Although many previous randomized clinical trials established that $\mathrm{ACE}$ inhibitors ${ }^{42,45}$ and $\mathrm{ARBs} \mathrm{s}^{56,59,61,95}$ reduce heart failure hospitalization, the patients in those studies were at higher risk for heart failure or left ventricular hypertrophy. Other studies with ACE inhibitors ${ }^{48,96}$ and $\mathrm{ARBs}^{97}$ in low-risk patients did not show a decrease in heart failure hospitalization. ${ }^{48,96}$ In ONTARGET, heart failure hospitalization rates were similar for telmisartan and ramipril (4.6\% versus $4.1 \%$ ). In TRANSCEND, rates of myocardial infarction were also lower than in HOPE (1.09\% versus $3.06 \%$ per year). Thus, the TRANSCEND population was altogether a lower risk group for heart failure.

Second, the authors suggest that a similar lack of benefit in the primary composite outcome as in TRANSCEND was found in the ProFESS (Prevention Regimen for Effectively Avoiding Second Strokes) study comparing telmisartan with placebo over 2.5 years in patients with recent stroke. ${ }^{16,17,97}$ They show, in a prespecified analysis of the combined data of the two trials, a reduction in the primary composite outcome after six months (9.3 versus $10.8 \% ; P<0.001)$ but not before six months $(3.8 \%$ versus $3.4 \% ; P=0.074) .{ }^{17}$ This finding suggests that prolonged therapy is needed for the heart failure benefit to manifest in that low-risk population.

Third, because HOPE preceded ONTARGET and TRANSCEND by over five years, this may have influenced background therapies in both the treatment and placebo groups. Thus, statin use was higher in TRANSCEND than in previous trials. ${ }^{17}$ Higher diuretic and beta-blocker use may have impacted on heart failure, and higher antiplatelet use may have impacted on stroke.

Fourth, even in the population with low heart failure risk in TRANSCEND, the rate of myocardial infarction was lower with telmisartan versus placebo $(3.9 \%$ versus $5.0 \% ; P=0.059)$ and similar to that with the ACE inhibitor in ONTARGET (4.8\% versus $5.2 \%),{ }^{15}$ suggesting that the previously voiced 
concern with ARB use ${ }^{51,98}$ did not apply in these patients. The lower rate of stroke in TRANSCEND was not statistically significant $(3.8 \%$ versus $4.6 \% ; P=0.136)$ but the secondary composite outcome, including stroke, was significantly lower (13.0\% versus $14.8 \% ; P=0.048$ ). This beneficial effect of an ARB on cerebrovascular events is consistent with other reports. ${ }^{15,59}$ Fifth, an important finding is that even patients who experienced angioneurotic edema and other adverse effects on ACE inhibitors tolerated telmisartan.

\section{Telmisartan and risk of stroke in ProFESS}

Previous studies showed that ACE inhibitors and ARBs after remote stroke are beneficial. PROGRESS (the Perindopril Protection against Recurrent Stroke Study) showed lowering of blood pressure in patients with substantial elevation using an ACE inhibitor and diuretic reduced the risk of recurrent stroke. ${ }^{99}$ HOPE showed that an ACE inhibitor reduces the rate of stroke in patients with previous cardiovascular events or high-risk diabetes despite mild lowering of blood pressure. ${ }^{3}$ The ARB, eprosartan, reduced recurrent stroke compared with a calcium channel blocker despite similar blood pressure reduction. ${ }^{100}$ The ARB, candesartan, given early after a stroke reduced rates of death despite no blood pressure reduction. ${ }^{101}$

The ProFESS study ${ }^{16}$ compared telmisartan $80 \mathrm{mg}$ daily $(n=10,146)$ with placebo $(n=10,186)$ initiated early after an ischemic stroke, less than 90 days before randomization. Patients were aged 50 years or older, and mean ages were similar (telmisartan $66.1 \pm 8.6$ years, placebo $66.2 \pm 8.6$ years) The mean interval from stroke was 15 days. Baseline mean blood pressure averaged 144.1/83.8 $\mathrm{mmHg}$ for the two groups. The mean follow-up was 2.5 years. The data showed that telmisartan did not significantly lower the rate of recurrent stroke $(8.7 \%$ versus $9.2 \% ; P=0.23)$, major cardiovascular events $(13.5 \%$ versus $14.4 \% ; P=0.11)$, or new-onset diabetes $(1.7 \%$ versus $2.1 \% ; P=0.10)$. The reasons for the lack of benefit of telmisartan in that study are not clear. As suggested by the authors, the effect of telmisartan may be time-dependent because the 2.5 years was shorter compared with HOPE (4.5 years) and PROGRESS (4.0 years) which showed benefit. The lack of effect on new-onset diabetes is not consistent with previous studies that showed reduced risk of diabetes with ACE inhibitors and ARBs. ${ }^{102,103}$ In addition, the PPAR $\gamma$ activity of telmisartan should have resulted in benefit. However, the only large trial with diabetes as the primary outcome did not find significant benefit with ramipril, ${ }^{96}$ suggesting that other factors may be involved.
The ProFESS trial also compared the efficacy of prophylactic treatment using aspirin $25 \mathrm{mg}$ daily plus extendedrelease dipyridamole $200 \mathrm{mg}$ twice daily $(\mathrm{n}=10,181)$ versus clopidogrel $75 \mathrm{mg}$ daily $(\mathrm{n}=10,151)$ and either telmisartan $80 \mathrm{mg}$ daily $(\mathrm{n}=10,146)$ or placebo $(\mathrm{n}=10,186)$ on reduction of disability and recurrent strokes ${ }^{97}$ in patients with ischemic stroke. In this study too, the data did not show improvement in functional or cognitive outcome comparing the two antiplatelet treatments or telmisartan versus placebo. ${ }^{97}$

\section{Telmisartan and left ventricular hypertrophy}

ONTARGET and TRANSCEND also provided important new data on the effect of telmisartan on left ventricular hypertrophy in high-risk patients without heart failure. ${ }^{15}$ At entry, the prevalence of left ventricular hypertrophy based on electrocardiograms in the two cohorts was $12.4 \%$ and $12.7 \%$, respectively. Mean age was 66-67 years. In the ACE inhibitor-intolerant patients of TRANSCEND, telmisartan reduced the prevalence of left ventricular hypertrophy $(P=0.0017)$ compared with placebo at two years $(10.5 \%$ versus $12.7 \%)$ and five years $(9.9 \%$ versus $12.8 \%$ ). Importantly, telmisartan suppressed new-onset left ventricular hypertrophy $(P=0.0001)$ although left ventricular hypertrophy regression was similar. In the ACE inhibitortolerant patients of ONTARGET, left ventricular hypertrophy prevalence was lower with both telmisartan $(P=0.07)$ and the combination $(P=0.12)$ compared with ramipril alone, although the differences were not significant. Interestingly, new onset left ventricular hypertrophy was associated with a higher risk of the primary outcome during follow-up. Taken together, telmisartan was more effective than placebo in reducing left ventricular hypertrophy, and new onset left ventricular hypertrophy was reduced by $37 \%$. However, combination of telmisartan with ramipril was not superior to ramipril alone.

Eight points deserve mention. First, the placebo group received intensive therapy but no renin-angiotensin systemblocking drugs. Second, the telmisartan-induced decrease in left ventricular hypertrophy over placebo in TRANSCEND did not translate into decrease in heart failure, and the telmisartan-induced greater decrease in left ventricular hypertrophy over ramipril in ONTARGET did not affect outcome. Third, the lack of difference in left ventricular hypertrophy regression despite a significant decrease in new-onset left ventricular hypertrophy with telmisartan versus placebo in TRANSCEND may be due to the modest decrease in blood pressure with telmisartan. Fourth, the prognostic value of 
left ventricular hypertrophy regression may be reduced in hypertensive patients with left ventricular hypertrophy and diabetes compared with those with left ventricular hypertrophy but no diabetes. Fifth, it was unclear why the lower prevalence of left ventricular hypertrophy with telmisartan versus ramipril was not statistically significant when other studies showed comparable left ventricular hypertrophy regression with ACE inhibitors and ARBs. ${ }^{104}$ Due to cost, the study used electrocardiographic criteria for left ventricular hypertrophy rather than echocardiographic left ventricular mass. However, a substudy of 297 ONTARGET patients using magnetic resonance imaging at baseline and at two years showed no left ventricular hypertrophy in the majority at baseline, but a similar decrease in left ventricular mass in all three groups. ${ }^{105}$

Sixth, when left ventricular hypertrophy is present at baseline, greater left ventricular hypertrophy regression with an ARB than an ACE inhibitor may result from enhanced $\mathrm{AT}_{2}$ receptor activation during $\mathrm{AT}_{1}$ receptor blockade. ${ }^{44}$ This effect may be further amplified in hypertrophic hearts that have $\mathrm{AT}_{2}$ receptor upregulation, which leads to increased antiproliferative and antifibrotic effects (see Figure 1) that oppose AT receptor stimulation of hypertrophy and remodeling.

Seventh, the reason why combination therapy showed statistically nonsignificant lower left ventricular hypertrophy prevalence than with ramipril alone is unclear. It is possible that a decline in renal function with combined reninangiotensin system inhibition blunted the decrease in left ventricular hypertrophy. ${ }^{106}$ It is also possible that decreased angiotensin II stimulation of $\mathrm{AT}_{2}$ receptors during $\mathrm{ACE}$ inhibition limited the decrease in left ventricular hypertrophy. Eighth, the finding of increased risk of the primary outcome with left ventricular hypertrophy is consistent with HOPE, which showed that left ventricular hypertrophy by electrocardiographic voltage criteria was an independent predictor of outcome in high-risk patients. In addition, subendocardial ischemia associated with concentric left ventricular hypertrophy in the presence or absence of coronary disease, may also increase risk.

\section{Meta-analysis of randomized clinical trials on telmisartan in hypertension}

A recent meta-analysis of randomized clinical trials of telmisartan versus ACE inhibitors for patients with hypertension (mean age 40-75 years) showed that telmisartan provides superior blood pressure control, with fewer adverse effects and better tolerability. ${ }^{107}$

\section{Conclusion}

The totality of the evidence from the two comparative megatrials, ONTARGET and TRANSCEND, and other studies suggest that the ARB, telmisartan, produces benefits beyond blood pressure reduction in older adult and younger elderly patients with vascular disease or high-risk diabetes that equal those of the ACE inhibitor, ramipril. Because telmisartan is equally effective and better tolerated than ramipril, this is an advantage for compliance in elderly patients. Thus, telmisartan appears to be an attractive alternative to an ACE inhibitor or a preferred ARB in ACE-intolerant patients. The finding of a greater blood pressure reduction with telmisartan suggests the need for careful dose titration and blood pressure monitoring in high-risk elderly patients, especially in view of age-related changes. The only small trial of telmisartan in elderly patients used careful dose titration and blood pressure monitoring, and showed effective blood pressure control. The possibility that the partial PPAR $\gamma$ activity of telmisartan might confer added benefits in highrisk elderly patients with diabetes is potentially important and needs clinical verification. The finding of increased adverse effects without added benefit with the combination of full-dose telmisartan and ramipril suggests that ARB-ACE inhibitor combinations should be either avoided or used with extreme caution in high-risk elderly patients. The potential importance of additional benefits of telmisartan beyond renin-angiotensin system inhibition on cardiovascular risk and new-onset diabetes deserves further study in carefully designed randomized clinical trials in elderly patients aged $>65$ years, $>75$ years, and $>85$ years, as well as nonelderly subjects.

\section{Acknowledgment}

This work was supported in part by Grant \# IAP99003 from the Canadian Institutes of Health Research, Ottawa, Ontario.

\section{Disclosure}

The author reports no conflict of interest in this work.

\section{References}

1. Lloyd-Jones D, Adams RJ, Brown TM, et al. Heart Disease and Stroke Statistics - 2010 Update: A Report from the American Heart Association Statistics Committee and Stroke Statistics Subcommittee. Circulation. 2010;121(7):e46-e215.

2. Yusuf S, Sleight P, Pogue J, Bosch J, Davies R, Dagenais G. The Heart Outcomes Prevention Evaluation Study Investigators. Effects of an angiotensin-converting-enzyme inhibitor, ramipril, on cardiovascular events in high-risk patients. $N$ Engl J Med. 2000;342(3):145-153.

3. Heart Outcomes Prevention Evaluation Study Investigators. Effects of ramipril on cardiovascular and microvascular outcomes in people with diabetes mellitus: Results of the HOPE study and MICRO-HOPE substudy. Lancet. 2000;355(9200):253-259. 
4. Chobanian AV, Bakris GL, Black HR, et al; Joint National Committee on Prevention, Detection, Evaluation, and Treatment of High Blood Pressure. National Heart, Lung, and Blood Institute; National High Blood Pressure Education Program Coordinating Committee. Seventh report of the Joint National Committee on Prevention, Detection, Evaluation, and Treatment of High Blood Pressure. Hypertension. 2003;42(6):1206-1252

5. Chobanian AV, Bakris GL, Black HR, et al; National Heart, Lung, and Blood Institute Joint National Committee on Prevention, Detection, Evaluation, and Treatment of High Blood Pressure; National High Blood Pressure Education Program Coordinating Committee. The Seventh Report of the Joint National Committee on Prevention, Detection, Evaluation, and Treatment of High Blood Pressure: The JNC 7 report. JAMA. 2003;289(19):2560-2572.

6. Rosendorff C, Black HR, Cannon CP, et al. American Heart Association Council for High Blood Pressure Research; American Heart Association Council on Clinical Cardiology; American Heart Association Council on Epidemiology and Prevention. Treatment of hypertension in the prevention and management of ischemic heart disease: A scientific statement from the American Heart Association Council for High Blood Pressure Research and the Councils on Clinical Cardiology and Epidemiology and Prevention. Circulation. 2007; 115(21):2761-2788.

7. Mancia G, de Backer G, Dominiczak A, et al. 2007 Guidelines for the management of arterial hypertension: The Task Force for the Management of Arterial Hypertension of the European Society of Hypertension (ESH) and of the European Society of Cardiology (ESC). Eur Heart J. 2007;28(12):1462-1536.

8. Calhoun DA, Jones D, Textor S, et al. Resistant hypertension: Diagnosis, evaluation, and treatment. A scientific statement from the American Heart Association Professional Education Committee of the Council for High Blood Pressure Research. Hypertension. 2008;51(6):1403-1419.

9. Benson SC, Pershadsingh HA, Ho CI, et al. Identification of telmisartan as a unique angiotensin II receptor antagonist with selective PPARgamma-modulating activity. Hypertension. 2004;43(5): 993-1002.

10. Vitale C, Mercuro G, Castiglioni C, et al. Metabolic effect of telmisartan and losartan in hypertensive patients with metabolic syndrome. Cardiovasc Diabetol. 2005;4:6-13.

11. Scalera F, Martens-Lobenhoffer J, Bukowska A, Lendeckel U, Täger M, Bode-Böger SM. Effect of telmisartan on nitric oxide asymmetrical dimethylarginine system: Role of angiotensin II type 1 receptor gamma and peroxisome proliferator activated receptor gamma signaling during endothelial aging. Hypertension. 2008;51(3): 696-703.

12. Saitoh Y, Hongwei W, Ueno H, Mizuta M, Nakazato M. Telmisartan attenuates fatty-acid-induced oxidative stress and $\mathrm{NAD}(\mathrm{P}) \mathrm{H}$ oxidase activity in pancreatic beta-cells. Diabetes Metab. 2009;35(5): 392-397.

13. Jung AD, Kim W, Park SH, et al. The effect of telmisartan on endothelial function and arterial stiffness in patients with essential hypertension. Korean Circ J. 2009;39(5):180-184.

14. Singh S, Loke YK, Furberg CD. Thiazolidinediones and heart failure: A teleo-analysis. Diabetes Care. 2007;30(8):2148-2153.

15. Yusuf S, Teo KK, Pogue J, et al; ONTARGET Investigators. Telmisartan, ramipril, or both in patients at high risk for vascular events. $N$ Engl $J$ Med. 2008;358(15):1547-1559.

16. Yusuf S, Diener HC, Sacco RL, et al. Telmisartan to prevent recurrent stroke and cardiovascular events. New Engl J Med. 2008;359(12):1225-1237.

17. Yusuf S, Teo K, Anderson C, et al; Telmisartan Randomised AssessmeNt Study in ACE iNtolerant subjects with cardiovascular Disease (TRANSCEND) Investigators. Effects of the angiotensin-receptor blocker telmisartan on cardiovascular events in high-risk patients intolerant to angiotensin-converting enzyme inhibitors: A randomised controlled trial. Lancet. 2008;372(9644):1174-1183.
18. Verdecchia P, Sleight P, Mancia G, et al; ONTARGET/TRANSCEND Investigators. Effects of telmisartan, ramipril, and their combination on left ventricular hypertrophy in individuals at high vascular risk in the Ongoing Telmisartan Alone and in Combination With Ramipril Global End Point Trial and the Telmisartan Randomized Assessment Study in ACE Intolerant Subjects With Cardiovascular Disease. Circulation. 2009;120(14):1380-1389

19. Karlberg BE, Lins LE, Hermansson K. Efficacy and safety of telmisartan, a selective AT1 receptor antagonist, compared with enalapril in elderly patients with primary hypertension. TEES Study Group. J Hypertens. 1999;17(2):293-302.

20. Nakayama T, Masubuchi Y, Kawauchi K, et al. Beneficial effect of beraprost sodium plus telmisartan in the prevention of arterial stiffness development in elderly patients with hypertension and cerebral infarction. Prostaglandins Leukot Essent Fatty Acids. 2007;309(6):3-4.

21. Asmar R, Gosse P, Topouchian J, N'tela G, Dudley A, Shepherd GL. Effects of telmisartan on arterial stiffness in type 2 diabetes patients with essential hypertension. J Renin Angiotensin Aldosterone Syst. 2002;3(3):176-180.

22. Formosa V, Bellomo A, Iori A, et al. The treatment of hypertension with telmisartan in the sphere of circadian rhythm in metabolic syndrome in the elderly. Arch Gerontol Geriatr. 2009;49 Suppl 1:95-101.

23. Jugdutt BI. Aging and remodeling during healing of the wounded heart: Current therapies and novel drug targets. Curr Drug Targets. 2008;9(4):325-344.

24. Jugdutt BI. Aging and heart failure: Changing demographics and implications for therapy in the elderly. Heart Fail Rev. 2010;15(5):401-405.

25. Goldberg RJ, McCormick D, Gurwitz JH, et al. Age-related trends in short- and long-term survival after acute myocardial infarction: A 20-year population-based perspective (1975-1995). Am J Cardiol. 1998;82(11):1311-1317.

26. Davis BR, Vogt T, Frost PH, et al. Risk factors for stroke and type of stroke in persons with isolated systolic hypertension. Systolic Hypertension in the Elderly Program Cooperative Research Group. Stroke. 1998;29(7):1333-1340.

27. Wolf PA, D'Agostino RB, Belanger AJ, Kannel WB. Probability of stroke: A risk profile from the Framingham Study. Stroke. 1991;22(3):312-318.

28. White HD, Simes RJ, Anderson NE, et al. Pravastatin therapy and the risk of stroke. $N$ Engl J Med. 2000;343(5):317-326.

29. Yusuf $S$, Hawken $S$, Ounpuu $S$, et al; INTERHEART Study Investigators. Effect of potentially modifiable risk factors associated with myocardial infarction in 52 countries (the INTERHEART study): Case-control study. Lancet. 2004;364(9438):937-952.

30. Jelani A, Jugdutt BI. STEMI and heart failure in the elderly: Role of adverse remodeling. Heart Fail Rev. 2010;15(5):513-521.

31. Wolf PA, D'Agostino RB, O'Neal MA, et al. Secular trends in stroke incidence and mortality. The Framingham Study. Stroke. 1992;23(11): $1551-1555$.

32. Turnbull F; Blood Pressure Lowering Treatment Trialists' Collaboration. Effects of different blood-pressure-lowering regimens on major cardiovascular events: Results of prospectively-designed overviews of randomised trials. Lancet. 2003;362(9395):1527-1535.

33. Tehrani F, Phan A, Chien CV, Morrissey RP, Rafique AM, Schwarz ER. Value of medical therapy in patients $>80$ years of age with heart failure and preserved ejection fraction. Am J Cardiol. 2009;103(6):829-833.

34. Jugdutt BI. Heart failure in the elderly: Advances and challenges. Expert Rev Cardiovasc Ther. 2010;8(5):695-715.

35. Kannel WB, McGee DL. Diabetes and cardiovascular disease. The Framingham study. JAMA. 1979;241(19):2035-2038.

36. Wingard DL, Barrett-Connor E. Heart disease and diabetes. In: Harris MJ, Cowie CC, Stern MS, Boyko EJ, Reiber GE, Bennett PH, editors. Diabetes in America. 2nd ed. Washington, DC: National Institutes of Health; 1995.

37. Gu K, Cowie CC, Harris MI. Diabetes and decline in heart disease mortality in US adults. JAMA. 1999;281(14):1291-1297.

38. Fowler MJ. Microvascular and macrovascular complications of diabetes. Clin Diabetes. 2008;26(2):77-82. 
39. Lonn EM, Yusuf S, Jha P, et al. Emerging role of angiotensin-converting enzyme inhibitors in cardiac and vascular protection. Circulation. 1994;90(4):2056-2069.

40. The SOLVD Investigators. Effect of enalapril on survival in patients with reduced left ventricular ejection fractions and congestive heart failure. N Engl J Med. 1991;325(5):293-302.

41. Pfeffer MA, Braunwald E, Moyé LA, et al. Effect of captopril on mortality and morbidity in patients with left ventricular dysfunction after myocardial infarction. Results of the survival and ventricular enlargement trial. The SAVE Investigators. $N$ Engl J Med. 1992;327(10):669-677.

42. Fox KM; The EURopean trial On reduction of cardiac events with Perindopril in stable coronary Artery disease Investigators. Efficacy of perindopril in reduction of cardiovascular events among patients with stable coronary artery disease: Randomised, double-blind, placebo-controlled, multicentre trial (the EUROPA study). Lancet. 2003;362(9386):782-788.

43. Pitt B, O'Neill B, Feldman R, et al; QUIET Study Group. The QUinapril Ischemic Event Trial (QUIET): Evaluation of chronic ACE inhibitor therapy in patients with ischemic heart disease and preserved left ventricular function. Am J Cardiol. 2001;87(9):1058-1063.

44. Braunwald E, Domanski MJ, Fowler SE, et al; PEACE Trial Investigators. Angiotensin-converting-enzyme inhibition in stable coronary artery disease. N Engl J Med. 2003;362(20):782-788.

45. Dagenais GR, Pogue J, Fox K, Simoons ML, Yusuf S. Angiotensinconverting-enzyme inhibitors in stable vascular disease without left ventricular systolic dysfunction or heart failure: a combined analysis of three trials. Lancet. 2006;368(9535):581-588.

46. Lewis EJ, Hunsicker LG, Bain RP, Rohde RD. The effect of angiotensinconverting-enzyme inhibition on diabetic nephropathy. The Collaborative Study Group. N Engl J Med. 1993;329(20):1456-1462.

47. Bosch J, Lonn E, Pogue J, Arnold JM, Dagenais GR, Yusuf S; HOPE/ HOPE-TOO Study Investigators. Long-term effects of ramipril on cardiovascular events and on diabetes: Results of the HOPE study extension. Circulation. 2005;112(9):1339-1346.

48. Patel A; ADVANCE Collaborative Group. Effects of a fixed combination of perindopril and indapamide on macrovascular and microvascular outcomes in patients with type 2 diabetes mellitus (the ADVANCE trial) A randomised controlled trial. Lancet. 2007;370(9590):829-840.

49. Jugdutt BI. Valsartan in the treatment of heart attack survivors. Vasc Health Risk Manag. 2006;2(2):125-138.

50. Kjeldsen SE, Lyle PA, Tershakovec AM, et al. Targeting the reninangiotensin system for the reduction of cardiovascular outcomes in hypertension: Angiotensin-converting enzyme inhibitors and angiotensin receptor blockers. Expert Opin Emerg Drugs. 2005;10(4):729-745.

51. Strauss MH, Hall AS. Angiotensin receptor blockers may increase risk of myocardial infarction: Unraveling the ARB-MI paradox. Circulation. 2006;114(8):838-854

52. Campbell DJ, Krum H, Esler MD. Losartan increases bradykinin levels in hypertensive humans. Circulation. 2005;111(3):315-320.

53. McKelvie RS, Yusuf S, Pericak D, et al. Comparison of candesartan, enalapril, and their combination in congestive heart failure: Randomized evaluation of strategies for left ventricular dysfunction (RESOLVD) pilot study. The RESOLVD Pilot Study Investigators. Circulation. 1999;100(10):1056-1064.

54. Tikkanen I, Omvik P, Jensen HA. Comparison of the angiotensin II antagonist losartan with the angiotensin converting enzyme inhibitor enalapril in patients with essential hypertension. $J$ Hypertens. 1995;13(11):1343-1351

55. Holwerda NJ, Fogari R, Angeli P, et al. Valsartan, a new angiotensin II antagonist for the treatment of essential hypertension: Efficacy and safety compared with placebo and enalapril. J Hypertens. 1996;14(9):1147-1151.

56. Chan P, Tomlinson B, Huang TY, Ko JT, Lin TS, Lee YS. Doubleblind comparison of losartan, lisinopril, and metolazone in elderly hypertensive patients with previous angiotensin-converting enzyme inhibitor-induced cough. J Clin Pharmacol. 1997;37(3):253-257.
57. Granger CB, McMurray JJ, Yusuf S, et al; CHARM Investigators and Committees. Effects of candesartan in patients with chronic heart failure and reduced left-ventricular systolic function intolerant to angiotensinconverting-enzyme inhibitors: The CHARM-Alternative trial. Lancet. 2003;362(9386):772-776.

58. Cohn JN, Tognoni G; for the Valsartan Heart Failure Trial Investigators. A randomized trial of angiotensin receptor blocker valsartan in chronic heart failure. $N$ Engl J Med. 2001;345(23):1667-1675.

59. McMurray JJ, Ostergren J, Swedberg K, et al; CHARM Investigators and Committees. Effects of candesartan in patients with chronic heart failure and reduced left-ventricular systolic function taking angiotensinconverting-enzyme inhibitors: The CHARM-Added trial. Lancet. 2003;362(9386):767-771

60. Dahlof B, Devereux RB, Kjeldsen SE, et al; LIFE Study Group. Cardiovascular morbidity and mortality in the Losartan Intervention For Endpoint reduction in hypertension study (LIFE): A randomised trial against atenolol. Lancet. 2002;359(9311):995-1003.

61. Dickstein K, Kjekshus J; OPTIMAAL Steering Committee of the OPTIMAAL Study Group. Effects of losartan and captopril on mortality and morbidity in high-risk patients after acute myocardial infarction: The OPTIMAAL randomised trial. Optimal Trial in Myocardial Infarction with Angiotensin II Antagonist Losartan. Lancet. 2002;360(9335): 752-760.

62. Pfeffer MA, McMurray JJ, Velazquez EJ, et al; Valsartan in Acute Myocardial Infarction Trial Investigators. Valsartan, captopril, or both in myocardial infarction complicated by heart failure, left ventricular dysfunction, or both. N Engl J Med. 2003;349(20):1893-1906.

63. Volpe M, Mancia G, Trimarco B. Angiotensin II receptor blockers and myocardial infarction: Deeds and misdeeds. $J$ Hypertens. 2005;23(12):2113-2118.

64. Ries UJ, Mihm G, Narr B, et al. 6-Substituted benzimidazoles as new nonpeptide angiotensin II receptor antagonists: Synthesis, biological activity, and structure-activity relationships. J Med Chem. 1993;36(25):4040-4051.

65. Smith DHG, Neutel JM, Morgenstern P. Once-daily telmisartan compared with enalapril in the treatment of hypertension. Adv Ther. 1998; 15:229-240.

66. Neutel JM, Smith DHG. Dose response and antihypertensive efficacy of the AT1 receptor antagonist telmisartan in patients with mild to moderate hypertension. Adv Ther. 1998;15:206-217.

67. Larsen PD, Martin JL. Polypharmacy and elderly patients. AORN J. 1999;69(3):619-22, 625, 627-628.

68. Jones BA. Decreasing polypharmacy in clients most at risk. AACN Clin Issues. 1997;8(4):627-634.

69. Burrell LM, Johnston CI. Angiotensin II receptor antagonists. Potential in elderly patients with cardiovascular disease. Drugs Aging. 1997;10(6):421-434.

70. Picard F, Auwerx J. PPAR (gamma) and glucose homeostasis. Annu Rev Nutr. 2002;22:167-197.

71. Walczak R, Tontonoz P. PPARadigms and PPARadoxes: Expanding roles for PPARgamma in the control of lipid metabolism. J Lipid Res. 2002;43(2):177-186.

72. Wakino S, Law RE, Hsueh WA. Vascular protective effects by activation of nuclear receptor PPAR gamma. J Diabetes Complications. 2002;16(1):46-49.

73. Hsueh WA, Law R. The central role of fat and effect of peroxisome proliferator-activated receptor-gamma on progression of insulin resistance and cardiovascular disease. Am J Cardiol. 2003;92(4A): 3J-9J.

74. Schiffrin EL, Amiri F, Benkirane K, Iglarz M, Diep QN. Peroxisome proliferator-activated receptors: Vascular and cardiac effects in hypertension. Hypertension. 2003;42(4):664-668.

75. Kotchen TA. Attenuation of hypertension by insulin-sensitizing agents Hypertension. 1996;28(2):219-223.

76. Verma S, Bhanot S, Arikawa E, Yao L, McNeill JH. Direct vasodepressor effects of pioglitazone in spontaneously hypertensive rats. Pharmacology. 1998;56(1):7-16. 
77. Buchanan TA, Meehan WP, Jeng YY, et al. Blood pressure lowering by pioglitazone. Evidence for a direct vascular effect. J Clin Invest. 1995;96(1):354-360.

78. Nesto RW, Bell D, Bonow RO, et al. Thiazolidinedione use, fluid retention, and congestive heart failure: a consensus statement from the American Heart Association and American Diabetes Association. Diabetes Care. 2004;27(1):256-263.

79. Shiomi T, Tsutsui H, Hayashidani S, et al. Pioglitazone, a peroxisome proliferator-activated receptor-gamma agonist, attenuates left ventricular remodeling and failure after experimental myocardial infarction. Circulation. 2002;106(24):3126-3132.

80. Cao Z, Ye P, Long C, et al. Effect of pioglitazone, a peroxisome proliferator-activated receptor gamma agonist, on ischemia-reperfusion injury in rats. Pharmacology. 2007;79(3):184-192.

81. Yue TL, Chen J, Bao W, et al. In vivo myocardial protection from ischemia/reperfusion injury by the peroxisome proliferatoractivated receptor-gamma agonist rosiglitazone. Circulation. 2001;104(21):2588-2594.

82. Lygate CA, Hulbert K, Monfared M, et al. The PPARgamma-activator rosiglitazone does not alter remodeling but increases mortality in rats post-myocardial infarction. Cardiovasc Res. 2003;58(3):632-637.

83. Graham DJ, Ouellet-Hellstrom R, MaCurdy TE, et al. Risk of acute myocardial infarction, stroke, heart failure, and death in elderly Medicare patients treated with rosiglitazone or pioglitazone. JAMA. 2010;304(4):411-418.

84. Zhang H, Zhang A, Kohan DE, Nelson RD, Gonzalez FJ, Yang T. Collecting duct-specific deletion of peroxisome proliferator-activated receptor gamma blocks thiazolidinedione-induced fluid retention. Proc Natl Acad Sci U S A. 2005;102(26):9406-9411.

85. Parhofer KG, Münzel F, Krekler M. Effect of the angiotensin receptor blocker irbesartan on metabolic parameters in clinical practice: The DO-IT prospective observational study. Cardiovasc Diabetol. 2007;6:36.

86. Brenner BM, Cooper ME, de Zeeuw D, et al; RENAAL Study Investigators. Effects of losartan on renal and cardiovascular outcomes in patients with type 2 diabetes and nephropathy. $N$ Engl J Med. 2001;345(12):861-869.

87. Naito T, Ma LJ, Yang H, et al. Angiotensin type 2 receptor actions contribute to angiotensin type 1 receptor blocker effects on kidney fibrosis. Am J Physiol Renal Physiol. 2010;298(3):F683-F691.

88. Barnett A. Preventing renal complications in type 2 diabetes: Results of the diabetes exposed to telmisartan and enalapril trial. J Am Soc Nephrol. 2006;17(4 Suppl 2):S132-135.

89. Phillips CO, Kashani A, Ko DK, Francis G, Krumholz HM. Adverse effects of combination angiotensin II receptor blockers plus angiotensinconverting enzyme inhibitors for left ventricular dysfunction: A quantitative review of data from randomized clinical trials. Arch Intern Med. 2007;167(18):1930-1936.

90. Jugdutt BI. Myocardial salvage by intravenous nitroglycerin in conscious dogs: Loss of beneficial effect with marked nitroglycerin-induced hypotension. Circulation. 1983;68(3):673-684.

91. Jugdutt BI, Warnica JW. Intravenous nitroglycerin therapy to limit myocardial infarct size, expansion, and complications. Effect of timing, dosage, and infarct location. Circulation. 1988;78(4):906-919.

92. Jugdutt BI, Warnica JW. Tolerance with low dose intravenous nitroglycerin therapy in acute myocardial infarction. Am J Cardiol. 1989;64(10):581-587.

\section{Clinical Interventions in Aging}

\section{Publish your work in this journal}

Clinical Interventions in Aging is an international, peer-reviewed journal focusing on evidence-based reports on the value or lack thereof of treatments intended to prevent or delay the onset of maladaptive correlates of aging in human beings. This journal is indexed on PubMed Central, MedLine, the American Chemical Society's 'Chemical Abstracts Ser-
93. Jugdutt BI. Intravenous nitroglycerin unloading in acute myocardial infarction. Am J Cardiol. 1991;68(14):D52-D63.

94. Cruickshank JM, Thorp JM, Zacharias FJ. Benefits and potential harm of lowering high blood pressure. Lancet. 1987;1(8533):581-584.

95. Julius S, Kjeldsen SE, Weber M, et al; for the VALUE trial group. Outcomes in hypertensive patients at high cardiovascular risk treated with regimens based on valsartan or amlodipine: The VALUE randomised trial. Lancet. 2004;363(9426):2022-2031.

96. Bosch J, Yusuf S, Gerstein HC, et al; DREAM Trial Investigators. Effect of ramipril on the incidence of diabetes. $N$ Engl J Med. 2006;355(15):1551-1562.

97. Diener HC, Sacco RL, Yusuf S, et al; Prevention Regimen for Effectively Avoiding Second Strokes (PRoFESS) study group. Effects of aspirin plus extended-release dipyridamole versus clopidogrel and telmisartan on disability and cognitive function after recurrent stroke in patients with ischaemic stroke in the Prevention Regimen for Effectively Avoiding Second Strokes (PRoFESS) trial: A double-blind, active and placebo-controlled study. Lancet Neurol. 2008;7(10):875-884.

98. Verma S, Strauss M. Angiotensin receptor blockers and myocardial infarction. BMJ. 2004;329(7477):1248-1249.

99. PROGRESS Collaborative Group. Randomised trial of a perindopril-based blood-pressure-lowering regimen among 6,105 individuals with previous stroke or transient ischaemic attack. Lancet. 2001;359(9287):1033-1041.

100. Schrader J, Lüders S, Kulschewski A, et al, MOSES Study Group. Morbidity and Mortality After Stroke, eprosartan compared with nitrendipine for secondary prevention: Principal results of a prospective randomized controlled study (MOSES). Stroke. 2005;36(6):1218-1226.

101. Schrader J, Lüders S, Kulschewski A, et al; Acute Candesartan Cilexetil Therapy in Stroke Survivors Study Group. The ACCESS Study: Evaluation of Acute Candesartan Cilexetil Therapy in Stroke Survivors. Stroke. 2003;34(7):1699-1703

102. Yusuf S, Gerstein H, Hoogwerf B, et al; HOPE Study Investigators. Ramipril and the development of diabetes. JAMA. 2001;286(15):1882-1885.

103. Elliott WJ, Meyer PM. Incident diabetes in clinical trials of antihypertensive drugs: A network meta-analysis. Lancet. 2007;369(9557):201-207.

104. Cuspidi C, Muiesan ML, Valagussa L, et al; CATCH investigators. Comparative effects of candesartan and enalapril on left ventricular hypertrophy in patients with essential hypertension: The candesartan assessment in the treatment of cardiac hypertrophy (CATCH) study. J Hypertens. 2002;20(11):2293-2300.

105. Cowan BP, Young AA, Anderson C, et al. Left ventricular mass and volume with telmisartan, ramipril, or combination in patients at high risk for vascular events: The Cardiac MRI sub-study to ONTARGET. Am J Cardiol. 2009;104(11):1484-1489.

106. Mann JF, Schmieder RE, McQueen M, et al; ONTARGET investigators. Renal outcomes with telmisartan, ramipril, or both, in people at high vascular risk (the ONTARGET study): A multicentre, randomised, double-blind, controlled trial. Lancet. 2008;372(9638):547-553.

107. Zou Z, Xi GL, Yuan HB, Zhu QF, Shi XY. Telmisartan versus angiotension-converting enzyme inhibitors in the treatment of hypertension: A meta-analysis of randomized controlled trials. J Hum Hypertens. 2009;23(5):339-349.

\section{Dovepress}

vice' (CAS), Scopus and the Elsevier Bibliographic databases. The manuscript management system is completely online and includes a very quick and fair peer-review system, which is all easy to use. Visit http://www.dovepress.com/testimonials.php to read real quotes from published authors. 